\title{
महाभारत में सनत्सुजातका अध्यात्मज्ञान
}

\author{
Dr. Sureshbhai Bahadurbhai Patel
}

प्रस्तावना

नमोडस्तु ते व्यास विशालबुद्धे फुल्लारविन्दायतपत्रनेत्र ।

येन त्वया भारततैलपूर्णः प्रज्वालितो ज्ञानमयः प्रदीपः।।1

महाभारत भारतीय संस्कृतिका विश्वकोश कहाजाता है। महाभारत में उचित हि कहा है कि, “ यन्न भारते तन्न भारते ।"2 अर्थात " जो महाभारत में नहीं वह भारत में नहीं।" समाज जीवनकी ऐसी कोई समस्या नहीं जिनको महर्षि व्यासने स्पर्श नहीं किया हो । महाभारतकी द्रढ़ प्रतीति थी कि - "न मानुषात् श्रेप्ठतरं हि कश्चित्।"3 व्यासजीने मानव जीवनके चार पुरुषार्थोकी विस्तृत चर्चा की है, जिसका महात्म्य बताते हुए कहा गया है कि -

धर्मे चार्थे च कामे च मोक्षे च भरतर्षभः।

यदिहास्ति तदन्यत्र यन्नेहास्ति न तत्कृचित् $1{ }^{4}$

विश्वप्रसिद्ध श्रीमद्वेदव्यास विरचित ऐतिहासिक महाभारत नामका महाकाव्य है। यह महाभारत महाकाव्य अठ्ठारह पर्वो में और एकसो उपपर्वो में विभाजित है। बाण और सुबंधुकी गद्य कथाओं से जाना जाता है, कि इशुकी षष्ठी सताब्दी या उनसे पूर्व उनका यह 'शतसाहस्ती' संहिता यानेकी एक लक्ष श्रोकवाला स्वरूप प्रचलित था -

\section{इदं शतसहस्रं हि श्लोकानां पुण्यकर्माणाम्। सत्यावत्यात्मजेनेह व्याख्यातममितौजसा $\|^{5}$}

\footnotetext{
1. महाभारत महात्म्य, महाभारत, गीताप्रेस गोरखपुर।

2. व्यासस्तुति, महाभारत, गीताप्रेस गोरखपुर ।

3. शान्तिपर्व : 299/20, महाभारत, गीताप्रेस गोरखपुर ।

4. महाभारत महात्म्य : $63 / 53$, महाभारत, गीताप्रेस गोरखपुर ।

5. महाभारत : $1 / 56 / 13$, महाभारत, गीताप्रेस गोरखपुर ।
} 
महाभारतके उद्योगपर्व में ‘सनत्सुजातीय दर्शन' नामक मर्मस्पर्शी दिव्य उपाख्यान है, वह चार अध्याय में विभक्त और करीबन एकसो उनपचास श्लोक में वर्णित है। जिस में वैशम्पायन, धृतराष्ट्र और सनत्सुजात यह तीन पात्र के संवाद में मर्मस्पर्शी जैसे की सृष्टि, उत्पत्ति, मृत्यु, लोक-लोकांतर, धर्म, अधर्म, ज्ञान, तप, ब्रह्मविद्या, ब्रह्मचर्य, ब्रह्मका स्वरुप, आत्माका स्वरुप इत्यादिका तत्त्वज्ञान प्रदर्शित होता है।

'तत्वज्ञान' शब्द में दो शब्द हे 'तत्त्व' और 'ज्ञान' तत्व = तत् + त्व अर्थात् "मानव आत्माकी वास्तविक प्रकृति या विश्वव्यापी परमात्माके समनुरूप विराट सृष्टी या भौतिक संसार"6 और 'ज्ञान' अर्थात् ज्ञा + ल्युट् = जानना समझना अर्थात् आत्मसाक्षात्कार या परमात्मा से मिलनकी बात सिखलाता है ! अथवा तो विशेष कर उस धर्म और दर्शनकी ऊँची सच्चाईयों पर मनन से उतपन्न ज्ञान जो मनुष्य को अपनी प्रकृति या वास्तविकताको जानना ! 8 इसी प्रकार 'तत्वज्ञान' शब्दका अर्थघटन हो सकता है !

समग्र विश्व के लिए अंतिम लक्ष्य शांती और आत्यंतिक सुख है ! सुख ये भौतिक पदार्थो और परिस्थितिके आधिन नहीं है ! यह सर्वविदित सिद्धांत है ! मानवजीवनके सनातन सुखको ढूढने जब हम निकलते है तब निश्चिंत रूप से यह खजाना महाभारतके सनत्सुजातीय दर्शन में छुपा हुआ है यह स्वीकारना पड़ेगा यह सनातन ज्ञानका आदर्श आधुनिक समाजको अपनी प्रासंगिकता पूर्ण करता है !

मुख्यशब्द - महाभारत, सनत्सुजात, अध्यात्मज्ञान, ब्रह्मविद्या, मोक्ष ।

6. संस्कृत-हिन्दी कोश, मोतीलाल बनारसीदास पब्लिशर्स प्राइवेट लिमिटेड, दिल्ली।

7. संस्कृत-हिन्दी कोश, मोतीलाल बनारसीदास पब्लिशर्स प्राइवेट लिमिटेड, दिल्ली।

8. संस्कृत-हिन्दी कोश, मोतीलाल बनारसीदास पब्लिशर्स प्राइवेट लिमिटेड, दिल्ली। 
सनत्सुजात

ब्रहमा के चार मानसपुत्र में से एक है ! जिनका नाम सनत्सुजात है ! सनत्सुजात अर्थात् "सनत् सर्वदा सुष्ठु जातं जन्म यस्य नित्यकुमारत्वेन जरामरणरहितः।"9 'सनत्' शब्दका अर्थ होता है सर्वदा, सदा, निरन्तर, नित्यादि ! 10 ‘सुजात' अर्थात् ‘सुशोभनं सुन्दरं जन्म यस्य सः सुजातः!'11 जिनका जन्म नित्य प्राणियों के आत्मोत्थानके लिए शोभायमान रहता है ! भगवद भक्त सनत्सुजात भक्त और तत्त्वज्ञ है। ऐसे भगवद् भक्त सनत्सुजातका अमृतोपदेश महाभारत में बहुत ही सुप्रसिद्ध है। और प्रमुख अध्यात्म विषयों पर सनत्सुजात और धृतराष्ट्रके संवाद द्वारा जो तत्त्वज्ञान प्रसिद्ध है वो इस प्रकार है।

\section{सनतसुजातीय अध्यात्मज्ञान :}

\section{मृत्यु}

संसारका कोईभी व्यक्ति हो जो जन्मता है उसका मृत्यु निश्चिंत है । ओर जो मरता है उसका जन्म निश्चिंत है। जैसा की - "जातस्य हि ध्रुवो मृत्युध्रुवं जन्म मृत्स्य च ।"12 मृत्युके सबंध में अज्ञानी है वही भयभीत होता है !" मृत्यु संसार के समग्र प्राणियोंको भयभीत करता है। "अमृत्युः कर्मणा केचित मृतत्युर्नास्तीति चापरे ।"13 मृत्यु के बारे में सनत्सुजात कहता है कि कुछ लोगोंको मानना है कि मृत्यु नहीं है । यहाँ पर अधिकारीके भेद से दोनों पक्ष सत्य है। कुछ विद्वानोंका मानना है कि 'मोह' ही मृत्यु है। “प्रमादं वै मृत्युमहं ब्रवीमि सदाउप्रमादममृतत्वं ब्रवीमि।"14 यहाँ पर सनत्सुजातका मानना है कि प्रमाद ही मृत्यु है और अप्रमाद ही अमरता है । संसार में अधिकतर प्राणी अपने वास्तविक स्वरुपके बारे में सोचते नहीं ! मृत्यु क्या है ? मृत्यु किसकी होती है ? मृत्यु के बाद जीवात्मा की क्या गति होती है ? इत्यादि प्रश्नो पर कोई सोचने समझनेका प्रयास ही नहीं करता है। अत: इन सभी प्रश्नोका समाधान यहाँ पर सनत्सुजात करवाता है, कि मृत्यु नामका कोई वस्तु या व्यक्ति ब्रह्माण्ड में है ही नहीं । प्रमाद रूपी अज्ञान के दूर होने पर ही आवागमनरूप संसारचक्र से छुटकारा मिलता है। अत: आत्मज्ञान से ही जन्म-मरण से मुक्ति मिलती

\footnotetext{
9. सनत्सुजातीयदर्शनम्, पृ. 4, शारदा संस्कृत संस्थान, वाराणसी - 221002.

10. संस्कृत-हिन्दी कोश, मोतीलाल बनारसीदास पब्लिशर्स प्राइवेट लिमिटेड, दिल्ली।

11. सनत्सुजातीयदर्शनम्, भूमिका, शारदा संस्कृत संस्थान, वाराणसी - 221002.

12. श्रीमद्रगवद्रीता, $2 / 27$, गीताप्रेस गोरखपुर ।

13. सनत्सुजातीयदर्शनम्, 1/3, शारदा संस्कृत संस्थान, वाराणसी - 221002.

14. सनत्सुजातीयदर्शनम्, 1/4, शारदा संस्कृत संस्थान, वाराणसी - 221002.
} 
है । "परं ज्योतिरुपसंपद्य स्वेन रूपेणाभिनिष्पद्यन्ते ।"15 " एको बन्धुर्नास्ति ततो द्वितीयो यो हृच्छयस्तमहमनुब्रवीमीति।"16 "मृत्युर्वै तमः।"17 इत्यादि मृत्यु सम्बन्धी कई सन्दर्भ शास्त्रों में हैं।

मोह

सांसारिक भोगो और आसक्ति जैसे कि रूप, रस, गंन्ध, स्पर्श और शब्द इन पाच प्रकारके सांसारिक विषयो में कर्मफल भोगके रूपमें प्राप्त होते है, अतःआशक्ति ही इन्द्रियोंको अत्यन्त मोहित करनेवाली है। ये संसारके भोग्य पदार्थ मिथ्या है । फिरभी अज्ञानीका उनमे राग होने से प्रवृति भी स्वाभाविक होती है। "ब्रह्मसत्यं जगन्मिथ्य"18 मिथ्या वस्तुओंकी रागासक्ति से व्यथित चित पुरुष, प्रत्येक जन्म में उन्ही मिथ्या वस्तुओंको मनसे याद करता हुआ उनकी प्राप्ति और संसरण में उन्ही मिथ्या वस्तुओंको मनसे याद करता हुआ उनकी प्राप्ति और संसरण में तल्लीन रहता है। अतःविषयो से निवृत नही होती, इसीलिए परमात्मा में प्रवृति नहीं होती और आत्मज्ञान नहीं होता और आत्मज्ञान नहीं होने से महामोहकी निवृत्ति भी नहीं होती - 'तद् वै महामोहनमिन्द्रियाणामित्यार्थयोगेडस्य गतिर्हि नित्या।"19

\section{धर्म-अधर्म}

धृतराष्ट्र सनत्सुजातको धर्म और अधर्म के बारे में पूछता है कि - " यस्माद्धर्मानाचरन्तीह केचित् तथा धर्मान्केचिदिहाचरन्ति। धर्मः पापेन प्रतिहन्यते वा उताहो धर्मः प्रतिहन्ति पापम् ॥” 20 संसार में सत्त्वगुण-बहुल पुरुष सत्कर्म याने कि धर्मका आचरण करते है और रजस्तमोगुण-बहुल पुरुष दुष्कर्म याने अधर्मका आचरण करते है। तो क्या धर्म से अधर्म पराजित होता है अथवा अधर्म के द्वारा धर्म प्रतिघातित होता है। "भिद्यते हृदयग्रन्थिः छिद्यन्ते सर्वसंशयाः । क्षीयन्ते चास्य कर्माणि तस्मिन् दृष्टे परावरे ।।"21 आत्मविद् पुरुष पाप और पुण्य में एक सदृश स्थित रहकर भी उन दोनोंको अपने ज्ञानके द्वारा नष्ट कर देता है। क्योंकि धर्म अधर्म या पाप-पुण्य दोनों ही अज्ञानोत्पन्न है । इनकी सत्ता तब तक है जब तक अज्ञान है। आत्मज्ञान के द्वारा देहाभिमानके नष्ट होते ही पुण्य-पापकी भावना नष्ट हो जाती है। यह बात श्रुति-स्मृति और पुराणों में भी प्रसिद्ध है। साथ ही यह भी प्रसिद्ध है कि

\footnotetext{
15. छान्दोग्योपनिषद् $(8 / 12 / 2)$ गीताप्रेस गोरखपुर ।

16. महाभारत, अश्वमेघपर्व $-26 / 3$, महाभारत, गीताप्रेस गोरखपुर ।

17. बृहदारण्यकोपनिषद् $1 / 3 / 28$, गीताप्रेस गोरखपुर ।

18. व्रह्मसूत्रशांकरभाष्यम्, सरस्वती प्रकाशन अमदावाद ।

19. सनत्सुजातीयदर्शनम्, 1/3, शारदा संस्कृत संस्थान, वाराणसी - 221002.

20. सनत्सुजातीयदर्शनम्, 1/22, शारदा संस्कृत संस्थान, वाराणसी - 221002.

21. मुण्डकोपनिषद् $2 / 2 / 8$, ब्रह्मवर्चस, शान्तिकुअ्ज, हरिद्वार ।
} 
ज्ञान ही मनुष्यका आत्मकल्याणकारी परम पुरुषार्थ है । उसके न रहने पर देहाभिमानी जीवात्मा भविष्य के धर्माधर्म के फलरूप में पुण्य और पाप अर्थात् सुख और दुःख पाता है। ईश्वरार्पण बुद्धि से किया गया आत्मज्ञानी का धर्म बलवान् होता है। " विद्वान् धर्मो बलीयानिति तस्य विद्धि ।"22

$>$ ज्ञान और कर्म

ज्ञान हि मोक्षका साथन है और कर्म हि बन्धनका कारण है, जैसा कि "ज्ञान योगेन सांख्यानां कर्मयोगेन योगिनाम्।" 23 आत्मज्ञानी ज्ञान मार्ग से ब्रह्मभावको प्राप्त हो जाता है और कर्मयोगी कर्मोपासना के द्वारा स्वर्गादिको प्राप्त करता है। पुण्य क्षीण होने से पुनः मृत्यु लोको में आता है, लेकिन वही कर्मयोगी यदि निष्काम कर्मोपासना करता है तो फिर वो मुक्त हो जाता है।

\section{ब्रह्म-जीवकी एकता}

यहाँ पर प्रश्न होता है कि यह सम्पूर्ण जगत यदि परमात्माका स्वरूप हि है, तो उस अजन्मा सनातन पुरुषको सृष्टि रचना करके उसमें प्रविष्ट होनेके लिए कोन प्रेरित करता है ? यहाँ पर जीव और ब्रह्मका भेद विषयक एक महान दोष उपस्थित होता है, जबकि जीव और ब्रह्म में भेदकी कल्पना वेद विरुद्ध है। जीवोंका भोग्य पदार्थो से सम्बन्ध और उनके जीव रूपकी प्रतीति अनादि मायाके कारण ही होती है। परमात्मा ही अनादि मायाका आश्रय लेकर अपनेको विश्वके रूपमें प्रकट करता है। “इन्द्रो मायाभिः पुरुरूप ईयते।" 24 मायाके संयोग से परमात्मा में मिथ्याभूत जीवोंकी प्रतीति जल में सूर्यबिम्बकी प्रतीतिकी भांति है। जीवका यह विभेद औपाधिक है। अतः परमात्माके स्वरूप में इस भेद से कोई अपकर्ष नहीं होता । जीवके देहादि मायाके संसर्ग से ही बार-बार उत्पन्न होते है । "दोषो महानत्र विभेदयोगे ह्यनादियोगेन भवन्ति नित्याः । तथास्य नाधिक्यमपैति किश्चित् अनादियोगेन भवन्ति पुंसः 11 " 25 "जीवों ब्रह्मैव न परः" 26 "तत्वमसि" 27 “अहं ब्रह्मास्मि" 28 "प्रज्ञानं ब्रह्म" 29 "एकं सद् विप्राः बहुधा वदन्ति।" 30 " एक एव तु भूतात्मा

\footnotetext{
22. सनत्सुजातीयदर्शनम्, $1 / 24$, शारदा संस्कृत संस्थान, वाराणसी - 221002.

23. श्रीमदूगवद्रीता, $3 / 3$, गीताप्रेस गोरखपुर ।

24. बृहदारण्यकोपनिषद् $(2 / 5 / 19)$ गीताप्रेस गोरखपुर ।

25. सनत्सुजातीयदर्शनम्, $1 / 20$, शारदा संस्कृत संस्थान, वाराणसी - 221002.

26. ब्रह्मसूत्रशांकरभाष्यम्, सरस्वती प्रकाशन अमदावाद।

27 . छान्दोग्योपनिषद् $(6 / 8 / 7)$ गीताप्रेस गोरखपुर।

28. बृहदारण्यकोपनिषद् $1 / 4 / 10$, गीताप्रेस गोरखपुर ।

29. ऐतरेयोपनिषद् $1 / 2$, गीताप्रेस गोरखपुर ।

30. ऋग्वेद, $1 / 164 / 46$, स्वाध्याय मण्डल, किल्लापारडी, वलसाड ।
} 
भूते भूते व्यवस्थितः । एकधा बहुधा चैव दृश्यते जलचन्द्रवत् ॥"31 इत्यादि श्रुतिवचनोके द्वारा जिव-ब्रह्मका ऐक्य दर्शाता है।

जगत

"य एतद् वा भगवान् स नित्यो विकारयोगेन करोति विश्वम् । तथा च तच्छक्तिरिति स्म मन्यते तथार्थयोगे च भवन्ति वेदाः ।॥"32 सर्व शक्तिमान इश्वर नित्य, शुद्ध सर्वधर्म-विवर्जित है। वह अपनी माया से विश्वका जगतका निर्माण करता है। इश्वरकी शक्ति-माया उनसे अभिन्न है और संसारकी या जगतकी रचना में समर्थ है। इस बातको सनत्सुजात मानता है मायाके जगत्कर्तुत्व और इश्वरके अविकारित्व आदिके सम्बन्ध में वेद स्वयं प्रमाण है। "दैवी होषा गुणमयी मम माया दुरत्यया।"33 तथा "त्रिभिर्गुणमयैभावैरेभिः सर्वमिदं जगत।"34

\section{ब्रह्मका स्वरुप}

ब्रह्म अरूप है । सर्वथा विलक्षण और अनिर्वचनीय है । वह आत्मप्रकाश (ब्रह्मप्रकाश) किसीभी रंग में प्रतित नही होता । ब्रह्मरुपका आधार पृथ्वीभी नही है और अन्तरिक्ष भी नही है। "आभाति शुक्लमिव लोहितमिवाथो कृष्णमथार्जुनं काद्रवं वा । यद् ब्राह्मणः पश्यति यत्र विद्वान् कथं रूपं तदमृतमक्षरं परम् ॥" 35 धृतराष्ट्र पूछता है कि, ज्ञानी पुरुष अपने ज्ञानके द्वारा हृदय में जिस अविनाशी, सर्वव्यापक, सर्वश्रेष्ठ परमात्मतत्त्वका साक्षात्कार कर लेता है, उस परमात्म तत्त्वका रंग कैसा है ? क्या वह श्वेत है, काला है, कषाय है अथवा पीत वर्ण का है ? तब सनत्सुजात कहता है कि " नाभाति शुक्लमिव लोहितमिवाथो कृष्णमथार्जुनं काद्रवं वा । न पृथिव्यां तिष्ठति नान्तरिक्षे नैतत्समुद्रे सलिलं बिभर्ति ॥"36 वह आत्मप्रकाश या ब्रह्मप्रकाश शुक्ल, लोहित, कृष्ण, पीत आदि किसी भी रंग में प्रतीत नहीं होता । ब्रह्मरूपका आधार पृथ्वी भी नहीं है, अन्तरिक्ष भी नहीं है, उसे सागर भी नहीं धारण करता है, वह अरूप है। सर्वथा विलक्षण और अनिर्वचनीय है। "तद अक्षरसमुदभवं ब्रह्म "37 "ब्रह्मार्पणं ब्रह्महविर्व्रह्माग्रौ ब्रह्मणा हुतम् । ब्रह्नैव तेन गन्तव्यं ब्रह्मकर्म समाधिना

\footnotetext{
31. अमृत-बिन्दु उपनिषद्, 12 , गीताप्रेस गोरखपुर ।

32 . सनत्सुजातीयदर्शनम्, $1 / 21$, शारदा संस्कृत संस्थान, वाराणसी - 221002.

33. श्रीमद्रगवद्रीता, $7 / 14$, गीताप्रेस गोरखपुर ।

34 . श्रीमदूगवद्रीता, $7 / 13$, गीताप्रेस गोरखपुर ।

35. सनत्सुजातीयदर्शनम्, 4/19, शारदा संस्कृत संस्थान, वाराणसी - 221002.

36. सनत्सुजातीयदर्शनम्, 4/20, शारदा संस्कृत संस्थान, वाराणसी - 221002.

37. श्रीमद्रगवद्रीता, $3 / 15$, गीताप्रेस गोरखपुर ।
} 
11 "38 स्मृतियों में भी कहा गया है कि, "ईश्वरः सर्वभूतानां हृद्देशेर्जुन तिष्ठति।"39 यह ब्रह्म न नक्षत्र में है, और नहीं विद्युत में । उसका रूप बादलों में भी नहीं दिखता । यह ब्रह्म चारों वेदों में भी नहीं दिखाई देता है। इसका साक्षात्कार द्वादश व्रतधारी ब्राह्मण अपने अन्तःकरणमें करता है। यह ब्रह्म अज्ञानान्धकार से परे अविच्छित्र है। इसकी स्थिति प्रलय में भी रहती है। यह सूक्ष्म से भी सूक्ष्म है और पर्वतों से भी विशाल है। यह सम्पूर्ण जगत उसी ब्रह्म में स्थित और उसी से प्रभासित होता है । आत्मज्ञानी अपने ह्रदयमें ज्ञानयोगके द्वारा इसका साक्षात्कार करते है। और जो इस ब्रह्मको जानलेता है, वह मुक्त हो जाता है । " अणोरणीयान् सुमनास्सर्वभूतेष्ववस्थितः। पितरं सर्वभूतानां पुष्करे निहितं विदुः ।।" 40 मैं ही (ब्रह्म ही) सूक्ष्म से सूक्ष्म हूँ, समग्र प्राणियोंके जनक प्रत्यगात्माको विद्वान् अपने हृदयमें देखते है ।

\section{ब्रह्मविद्या}

वेदका आशय बहुंत ही गहन है। सभी मनुष्य वेदका तत्त्व नहीं समझ सकता । विद्या, अविद्या और सम्भूति, असम्भूतिका अर्थ विद्वानोंने अनेक प्रकार से किया है। “ विद्यां चाविद्यां च यस्तद्वेदोभयं सह। अविद्यया मृत्युं तीर्व्वा विद्ययामृतमश्रुते ।"*1 तथा "अन्धं तमः प्रविशन्ति येडसम्भूतिमुपासते। ततो भूय इव ते तमो य उ सम्भूत्यां रताः 11 " 42 यहाँ पर विद्वानोंने अनेक प्रकार से अर्थघटन किया है। यहाँ पहले विद्याअविद्या पर विचार करें तो विद्याका अर्थ ब्रह्मविद्या और अविद्या का अर्थ यज, दान, तप आदि कर्मोको करना इस प्रकार मानना ठीक है। क्योकि यहाँ विद्या- अविद्याके तत्त्वको न समझनेवालेकी निंदा और समझनेवालेकी प्रसंसा की है। अपरोक्षानुभूति में भी कहा गया है कि, " कुशला ब्रह्मवार्तायां वृत्तिहीनाः सुरागिणः। ते ह्यज्ञानितमा नूनं पुनरायान्ति यान्ति च ।" 43 जो ब्रह्मवार्ता में कुशल हैं किन्तु ब्राह्मीवृत्ति से रहित और रागयुक्त है, निश्चय ही वे अत्यंत अज्ञानी है और बारम्बार जन्मते-मरते रहते है। जिस तत्त्वज्ञान के विषय में अति शीघ्र ज्ञान प्राप्त होता है वह तत्त्वज्ञान इतनी शीघ्रता से कभी भी नहीं मिलता । उनकी प्राप्ति तब होती है, जब इन्द्रियोंका निरोध हो जाय । उनके बाद संकल्प-विकल्पात्मक मन जब बुद्धिगुहा में लीन हो जाता है और 'अहं ब्रह्मास्मि' केवल यही भाव बुद्धि में स्थित रहता है। तब एक प्रकारकी जो निरुद्ध

\footnotetext{
38. श्रीमद्रगवद्रीता, $4 / 24$, गीताप्रेस गोरखपुर ।

39. श्रीमद्रुगवद्रीता, $18 / 61$, गीताप्रेस गोरखपुर ।

40. सनत्मुजातीयदर्शनम्, 4/29, शारदा संस्कृत संस्थान, वाराणसी - 221002.

41 . ईशावास्योपनिषद् 11 , गीताप्रेस गोरखपुर।

42. ईशावास्योपनिषद् 12 , गीताप्रेस गोरखपुर ।

43. अपरोक्षानुभूतिः, चौखम्बा सुरभारती प्रकाशन, वाराणसी।
} 
सर्ववृत्तिक अवस्था होती है, वही ' ब्रह्मविद्या' है । उस ब्रह्मविद्या की प्राप्ति केवल ब्रह्मचर्य पालन से ही होती है, ऐसा सनत्सुजात का मानना है। जिस ब्रह्म को प्राप्तकर लोग मर्त्यलोकका परित्याग कर देते है।

\section{स्वानुभूति}

सनत्सुजात सभी प्रकारके संशयका निराकरण करते करते अंत में स्वानुभूति क्या है ? उसको समजाते हुए कहता है कि, मैं ही आपका वृद्ध पितामह, पिता एवं पुत्र हूँ। तुम लोग मेरी ही आत्मा में स्थित हो। किन्तु वास्तविक रूप से न तुम मेरे हो और न मैं तुम्हारा हूँ। आत्मा से अलग किसी का अस्तित्व नहीं है। समग्र संबंधोकी मान्यता भेद-व्यवहारके कारण है। अभेद दृष्टि होने पर सब कुछ एक आत्मा है। यथा - "पितामहोउस्मि स्थविरः पिता पुत्रश्व भारत। ममैव यूयमात्मस्था न मे यूयं न चाप्यहम् ॥" 44 और अंतिम श्लोक में स्वानुभूति के बारे में सनत्सुजात धृतराष्ट्र को समजाते है कि, आत्मा ही मेरा निवास स्थान है और आत्मा ही उत्पत्ति स्थान है। मैं जरा मरण से रहित हूँ। मैं ही अजन्मा, चराचरस्वरुप हूँ। मैं दिन-रात जागृत रहता हूँ। मुझे जानकर ज्ञानी पुरुष परमानन्द में निमग्र हो जाते हैं। यथा - " आत्मैव स्थानं मम जन्म चात्मा ओतप्रोतोऽ्हमजरप्रतिष्ठः। अजश्वरो दिवारात्रमतन्द्रितोऽहं मां विज्ञाय कविरास्ते प्रसन्नः ।"य5

निष्कर्ष

इस प्रकार सनत्सुजातीय दर्शन में अध्यात्मज्ञानका ज्ञानोपदेश गीता के उपदेश की तरह सारगर्भित, महत्वपूर्ण और मनन योग्य है। धृतराष्ट्र के मनमे जो अशांति, शंका, द्विधा, परावलम्बित्व आदि मानव सुलभ न्यूनता और मृत्युका भय देखा जाता है, उनका निराकरण करने के लिए महर्षि सनत्सुजात सम्यक् उपदेश दे कर ब्रह्मविद्याका उपदेश देकर पूर्ण करता है और उनके मनकी समस्याका समाधान करनेके लिये मर्मस्पर्शी जैसेकी सृष्टि, उत्पत्ति, मृत्यु, लोक-लोकांतर, धर्म, अधर्म, ज्ञान, तप, ब्रह्मविद्या, ब्रह्मचर्य, ब्रह्मका स्वरुप, आत्माका स्वरुप इत्यादिका अध्यात्मज्ञान प्रदर्शित करके मनकी समस्या का समाधान करता है।

\footnotetext{
44. सनत्सुजातीयदर्शनम्, 4/29, शारदा संस्कृत संस्थान, वाराणसी - 221002.

45. सनत्सुजातीयदर्शनम्, 4/30, शारदा संस्कृत संस्थान, वाराणसी - 221002.
} 


\section{संदर्भग्रंथ सूचि}

(1) सनत्सुजातीयदर्शनम्, शारदा संस्कृत संस्थान, वाराणसी - 221002.

(2) सनत्सुजातीयभाष्यम्, श्री शंकराचार्य ।

(3) अपरोक्षानुभूतिः, चौखम्बा सुरभारती प्रकाशन, वाराणसी।

(4) ईशावास्योपनिषद्, गीताप्रेस गोरखपुर ।

(5) श्रीमदूगवद्रीता, गीताप्रेस गोरखपुर ।

(6) बृहदारण्यकोपनिषद्, गीताप्रेस गोरखपुर ।

(7) ब्रह्मसूत्रशांकरभाष्यम्, सरस्वती प्रकाशन, अमदावाद ।

(8) छान्दोग्योपनिषद् , गीताप्रेस गोरखपुर ।

(9) ऐतरेयोपनिषद्, गीताप्रेस गोरखपुर ।

(10) ऋग्वेद, स्वाध्याय मणडल, किल्लापारडी, वलसाड ।

(11) अमृत-बिन्दु उपनिषद्, , गीताप्रेस गोरखपुर ।

(12) मुण्डकोपनिषद्, ब्रह्नवर्चस, शान्तिकुक्ज, हरिद्वार ।

(13) महाभारत, गीताप्रेस गोरखपुर ।

(14) संस्कृत-हिन्दी कोश, मोतीलाल बनारसीदास पब्लिशर्स प्राइवेट लिमिटेड, दिल्ली ।

\section{Dr. Sureshbhai Bahadurbhai Patel Pradhyapak Department of Traditional Sanskrit Studies The Maharaja Sayajirao University of Baroda Mo. No. 09898723644 Email-sureshpatel452@gmail.com}

